\title{
Effect of dried California Mission figs on mineral status and food replacement
}

\author{
Heba K Alshaeri ${ }^{1,2, *}$, Zuhair S Natto ${ }^{3,4}$, Serena Tonstad ${ }^{5}$, Ella Haddad ${ }^{1}$ and \\ Karen Jaceldo-Siegl ${ }^{1}$ \\ 'Department of Nutrition, School of Public Health, Loma Linda University, Loma Linda, CA, USA: ${ }^{2}$ Department of \\ Pharmacology, School of Pharmaceutical Science, Massachusetts College of Pharmacy and Health Sciences, 3660 \\ Mystic Valley Parkway AptW614, Medford, MA 02155, USA: ${ }^{3}$ Department of Epidemiology and Biostatistics, \\ School of Public Health, Loma Linda University, Loma Linda, CA, USA: ${ }^{4}$ Department of Dental Public Health, School \\ of Dentistry, King Abdulaziz University, Jeddah, Saudi Arabia: ${ }^{5}$ Department of Health Promotion and Education, \\ School of Public Health, Loma Linda University, Loma Linda, CA, USA
}

Submitted 16 February 2014: Final revision received 21 June 2014: Accepted 24 June 2014: First published online 22 August 2014

\begin{abstract}
Objective: Figs are a rich source of several different minerals and fibres. We studied the effect of the consumption of dried California Mission figs on mineral and nutrient levels, as well as the effect of the addition of figs to a self-selected habitual diet on dietary patterns.

Design: A crossover randomized controlled trial study design in which participants with a mean of age of approximately 56 years were randomly assigned to eat either their usual diet for 5 weeks or to add dried California Mission figs ( $120 \mathrm{~g} / \mathrm{d})$ to their usual diet for 5 weeks, after which they crossed over to the other group for an additional 5 weeks. Six $24 \mathrm{~h}$ dietary recalls and four blood samples were obtained from each participant.

Setting: Loma Linda University School of Public Health, USA.

Subjects: A follow-up study using data collected from eighty-eight American males and females from September to December 2008.

Results: Diets reported in the $24 \mathrm{~h}$ dietary recall during the fig-supplemented diet period were significantly higher in $\mathrm{Ca}$ and $\mathrm{K}$ in the dietary and total phase $(P$ value $<0.05)$. Nevertheless, data on mineral levels in the body gathered by means of biochemical analyses from blood samples were nearly the same for both the figs-added and the participants' standard diet. The estimated displacement suggests that eating figs resulted in the elimination of $4 \%$ of desserts, $5 \%$ of vegetables, $10 \%$ of dairy products, $23 \%$ of grain products and $168 \%$ of beverages from other sources that participants would otherwise consume.

Conclusions: Based on $24 \mathrm{~h}$ dietary recalls, the daily consumption of figs may increase the intake of several different minerals. However, mineral levels in blood samples were not altered significantly.
\end{abstract}

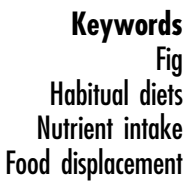

Usual dietary patterns and health conditions ${ }^{(1,2)}$ are clearly associated. Based on several scientific articles that focus on the role of nutrition in health, a number of different organizations, including the WHO, the Institute of Medicine's Food and Nutrition Board and the European Food Safety Authority, issue and periodically update dietary recommendations and guidelines in order to assist the public with avoiding unhealthy lifestyles and preventing such chronic diseases as obesity, diabetes mellitus, CVD, osteoporosis and several cancers related to $\operatorname{diet}^{(3-6)}$. Most guidelines offer recommendations regarding amounts and food types that should be consumed depending on age, gender and whether or not an individual is lactating or pregnant; these recommendations serve to help individuals maintain or improve their health. Different food groups, such as fruits, vegetables and dairy products, have been integrated into these guidelines, with the consumption of some foods in particular being more beneficial than others. One food with excellent potential that has not yet been fully investigated is figs.

California Mission figs (Ficus carica 'Mission') have two crops each year. The first crop is generally sold as fresh figs, whereas the second crop is harvested in late June to be sold as dried figs ${ }^{(7)}$. Dried figs have a higher nutrient density, fibre content, shelf-life and phenol antioxidant content in 
Table 1 Mineral, free and total phenol composition of dried California Mission figs per $100 \mathrm{~g}$

\begin{tabular}{lc}
\hline Variable & Value per $100 \mathrm{~g}$ \\
\hline $\mathrm{K}(\mathrm{mg})$ & 680 \\
Total phenol $(\mathrm{mg})$ & 320 \\
Free phenol $(\mathrm{mg})$ & 256 \\
$\mathrm{Ca}(\mathrm{mg})$ & 162 \\
$\mathrm{Mg}(\mathrm{mg})$ & 68 \\
$\mathrm{P}(\mathrm{mg})$ & 67 \\
$\mathrm{Na}(\mathrm{mg})$ & 10 \\
$\mathrm{Fe}(\mathrm{mg})$ & 2.03 \\
$\mathrm{Zn}(\mathrm{mg})$ & 0.55 \\
$\mathrm{Mn}(\mathrm{mg})$ & 0.510 \\
$\mathrm{Cu}(\mathrm{mg})$ & 0.287 \\
$\mathrm{Se}(\mu \mathrm{g})$ & 0.6 \\
\hline Sources: US Department of Agriculture $^{(17)}$ and Vinson \\
et al. ${ }^{\left({ }^{2}\right)}$
\end{tabular}

comparison with other fruit ${ }^{(8,9)}$. The mineral and phenol contents of $100 \mathrm{~g}$ of figs are presented in Table 1.

To the best of our knowledge, no published studies focus on the effect of fig consumption on mineral and nutrient levels or food displacement. Food displacement is important as 'an inverse measure of the degree to which the fig supplement induced a change in the content of a particular food in the supplemented diet ${ }^{(10)}$. To understand the effect of the consumption of dried California Mission figs on different dietary and plasma minerals, we conducted a randomized controlled clinical trial with a group of participants in an effort to gain insight into fig consumption's effect on mineral and nutrient levels in the body. In addition, we studied the effect of fig intake on food displacement, or the replacement of foods normally eaten with another food - figs, in this case.

\section{Experimental methods}

The present study is a crossover randomized controlled trial conducted at the Loma Linda University School of Public Health from September through December, 2008. Participants were recruited and randomly selected from different communities in San Bernardino County, California. The study began with 2 weeks of participant screening, followed by the 10 -week intervention. The study was conducted according to the guidelines laid down in the Declaration of Helsinki and all procedures involving human subjects/patients were approved by the Institutional Review Board of Loma Linda University. Written informed consent was obtained from each participant. Information and flyers were posted at different local venues such as churches, business establishments and around the university campus. Demographic information and medical history were obtained from all participants by means of a self-reported health questionnaire.

Participants with a BMI of $18.5-35.0 \mathrm{~kg} / \mathrm{m}^{2}$ and no cigarette smoking within the past year were included. Exclusion criteria included: participants with a secondary cause of hyperlipidaemia such as kidney or liver disease; untreated hypothyroidism; use of any lipid-lowering drug within the past 2 months; type 1 diabetes or uncontrolled type 2 diabetes (glycated $\mathrm{Hb}$ (HbA1c) >7\%); TAG concentration $>300 \mathrm{mg} / \mathrm{dl}$; use of any treatment with oestrogen or steroid therapy in the last 3 months; a stated aversion to figs; consumption of certain dietary supplements such as Metamucil and sterol/stanol margarine; presence of chronic disease that may affect concentrations of lipids or markers of inflammation, such as cancer within the last 5 years; chronic rheumatological disease; chronic severe depression; or any condition that would interfere with the protocol such as drug abuse.

Initially, 102 adult males and females were randomly assigned using computer-generated numbers to either a figs-added diet or their usual diet for the first 5 weeks, and then switched to the other condition for the second 5 weeks. In the figs-added diet, each participant was consuming a pre-weighed, pre-packaged serving of $120 \mathrm{~g}$ of dried California Mission figs (twelve to fifteen figs) as part of their three meals per day diet for 5 weeks; the figs were provided by the California Fig Advisory Board. Participants were instructed to eat their regular diet but not to consume any figs other than those provided by the study. However, participants were allowed to replace selected desserts and sweets with figs in order to maintain their normal energy intake.

Participants attended a total of six visits at weeks 2, 4, 5 , 7, 9 and 10 (three times in each phase and a crossover visit in week 5) for researchers to collect vital signs, anthropometric measurements, $24 \mathrm{~h}$ dietary recalls and a short health questionnaire to note any changes in health or use of medications. Participants were asked to make up for any missed portions of figs by consuming them later in the day with meals or as a snack. Daily compliance with the assigned portions of figs was recorded on a compliance form. Each participant who completed the 12 -week study received a \$US 25 gift certificate.

\section{Dietary analyses}

The $24 \mathrm{~h}$ dietary recalls were performed six times at scheduled intervals and has been described extensively elsewhere ${ }^{(9)}$. The recalls were performed by registered dietitians and a trained graduate student by means of two telephone interviews and one in-person interview in each study phase. Two weekdays and one weekend were randomly selected in each phase for each participant by drawing from a box containing folded slips of paper with the day (Sunday through Friday), or as soon as possible if the interview was not possible on the drawn day. The Nutrition Data System for Research (NDSR) software ${ }^{(11)}$ was used for the $24 \mathrm{~h}$ dietary recall. Vinson's data ${ }^{(12)}$ were used to evaluate changes in fibre intake during each phase.

\section{Biochemical analyses}

All participants had blood samples drawn five times during the study, once at baseline and twice at the end of each 
phase separated by one week. Samples were drawn following an overnight fast between 06.30 and 09.00 hours; then separated by centrifugation at $1500 \mathrm{~g}$ and $4{ }^{\circ} \mathrm{C}$ for $10 \mathrm{~min}$, and aliquots of plasma and serum were stored at $-80^{\circ} \mathrm{C}$ until analyses. Tests for blood mineral concentrations, total phenols and antioxidant activity were performed at the nutrition laboratory at Loma Linda University.

Serum for analysis of $\mathrm{Mg}, \mathrm{K}$ and $\mathrm{Zn}$ was wet-ashed with nitric acid, dried, and concentrations of $\mathrm{K}, \mathrm{Zn}$ and $\mathrm{Mg}$ were measured by atomic absorption spectrophotometry in a Shimadzu AA-6300 instrument (Kyoto, Japan) according to the manufacturer's directions. Serum Fe was measured using the iron ferrozine reagent from Thermo Fisher Scientific (Waltham, MA, USA). Total phenolic content in plasma was measured by the Folin-Ciocalteau (FC) reagent as modified by Serafini et al. ${ }^{(13)}$ to remove protein interferences. Briefly, total phenolic concentrations of plasma samples were determined after a procedure of acid extraction, hydrolysis and protein precipitation with metaphosphoric acid $(0.75 \mathrm{~mol} / \mathrm{l})$. For hydrolysing the conjugated forms of polyphenols, hydrochloric acid was added to the sample, followed by sodium hydroxide in methanol. This step breaks the links of polyphenols with lipids and provides a first extraction of polyphenols. The final extraction of polyphenols was accomplished by adding 1:1 (v/v) solution of acetone and water. The results are expressed as gallic acid equivalents (GAE) in millimoles per litre.

To measure the antioxidant capacity of plasma, the ferricreducing ability of plasma (FRAP) assay as described by Benzie and Strain ${ }^{(14)}$ was used. The underlying principle of the assay is that at low $\mathrm{pH}$, the ferric (Fe III) tripyridyltriazine complex is reduced to the ferrous (Fe II) form and develops an intense blue colour with an absorption maximum at $593 \mathrm{~nm}$. Test conditions favour reduction of the complex, and thereby colour development, provided that reductants (antioxidants) are present. Absorbance changes are linear over a range of concentrations of the antioxidant mixtures found in plasma. The results are expressed as millmoles of antioxidant power per litre.

\section{Estimation of food displacement}

We followed the calculation method explained before in a previous publication from our group ${ }^{(10)}$. For food $i, H_{i}$ is the intake of a food during the usual diet; $S_{i}$ is the amount of fig intake in the added-figs diet phase; $A_{i}$ is the intake of that food during the added-figs diet period. Since the fig supplement was added to the habitual diet, the expected intake of that food in the supplemented diet is $H_{i}+S_{i}$. Displacement of that food $\left(D_{i}\right)$ was estimated by subtracting the observed intake of that food in the supplemented diet, $A_{i}$, from the expected intake of that food. Thus, $D_{i}=\left(H_{i}+S_{i}\right)-A_{i}$. Percentage displacement was calculated by $D_{i} / S_{i} \times 100$.

\section{Statistical analysis}

The sample size calculation was explained in a previous publication $^{(9)}$. Briefly, based on the estimated average serum LDL-cholesterol at baseline of about $130 \mathrm{mg} / \mathrm{dl}$, a significant reduction of LDL-cholesterol would be about $3.5 \%$. With SD of $8 \%$ we estimated that to achieve $80 \%$ power with $\alpha=0.05$, eighty-four participants were required. To allow for an attrition rate of up to $20 \%, 100$ participants were planned.

Following data entry of a random sample, comparisons were made across groups at the end of each period (Mann-Whitney test). A Wilcoxon signed-ranks test analysis was used to compare changes in different minerals in blood samples from the beginning and the end of each period. A general linear model of repeated-measures ANOVA analysis was done to determine if there was any change in any of the four measurements. The statistical software package utilized for analyses was SAS version 9.3.

\section{Results}

\section{Participants}

The characteristics of participants randomized to their usual diet or to an added-figs diet at screening are shown in Table 2.

\section{Dietary and plasma minerals}

During the added-figs phase, the intakes of $\mathrm{Ca}, \mathrm{Mg}$ and $\mathrm{K}$ were $130 \mathrm{mg}, 52 \mathrm{mg}$ and $580 \mathrm{mg}$ higher, respectively, than those in the usual diet (significant amounts). These results were found when figs were used in diets alone or when combined with supplements during the $24 \mathrm{~h}$ recall period $(P<0.05$; Table 3$)$. In addition, Table 3 shows that both Fe and $\mathrm{Cu}$ were higher $(P<0.05)$ during the added-figs phase than in the usual diet (Fe: $16.50 v .15 .16 \mathrm{mg}$; Cu: $1.98 v$. $1.68 \mathrm{mg}$ for 'dietary').

However, minerals reported by biochemical analyses of blood samples were almost similar during the figs-added and usual diet except for total phenols (FC), which was significant in repeated-measure ANOVA when all four

Table 2 Baseline characteristics of participants completing the study; American males and females ( $n$ 88), September-December 2008

\begin{tabular}{|c|c|c|}
\hline Variable & Mean or $n$ & SD or $\%$ \\
\hline Age (years) & 55.90 & $10 \cdot 64$ \\
\hline $\mathrm{BMI}\left(\mathrm{kg} / \mathrm{m}^{2}\right)$ & $26 \cdot 34$ & 3.74 \\
\hline \multicolumn{3}{|l|}{ Gender } \\
\hline Male & 29 & 33.0 \\
\hline Female & 59 & $67 \cdot 0$ \\
\hline \multicolumn{3}{|l|}{ BMl category } \\
\hline $18.0-24.99 \mathrm{~kg} / \mathrm{m}^{2}$ & 36 & 43.4 \\
\hline $25.0-29.99 \mathrm{~kg} / \mathrm{m}^{2}$ & 33 & $39 \cdot 8$ \\
\hline$\geq 30.0 \mathrm{~kg} / \mathrm{m}^{2}$ & 14 & $16 \cdot 9$ \\
\hline \multicolumn{3}{|l|}{ Race } \\
\hline White & 35 & $41 \cdot 7$ \\
\hline Black & 17 & $20 \cdot 2$ \\
\hline Hispanic & 14 & 21.4 \\
\hline Asian & 14 & $16 \cdot 7$ \\
\hline
\end{tabular}

Continuous variables are presented as mean and standard deviation; categorical variables as frequency and percentage. 
Table 3 Changes in the intakes of selected minerals, assessed by three $24 \mathrm{~h}$ recalls for each diet period, among American males and females ( $n$ 88), September-December 2008

\begin{tabular}{|c|c|c|c|c|c|c|c|c|c|c|}
\hline \multirow[b]{3}{*}{ Variable } & \multicolumn{4}{|c|}{ Added-figs diet } & \multicolumn{4}{|c|}{ Usual diet } & \multirow[b]{3}{*}{$P$ value for total } & \multirow[b]{3}{*}{$P$ value for dietary } \\
\hline & \multicolumn{2}{|c|}{ Dietary } & \multicolumn{2}{|c|}{ Total† } & \multicolumn{2}{|c|}{ Dietary } & \multicolumn{2}{|c|}{ Total† } & & \\
\hline & Mean & SD & Mean & SD & Mean & SD & Mean & SD & & \\
\hline $\mathrm{Ca}(\mathrm{mg})$ & 968.50 & $438 \cdot 15$ & 1192.52 & 580.96 & 831.89 & $462 \cdot 86$ & $1044 \cdot 33$ & 587.40 & $0.04^{*}$ & $<0.01^{*}$ \\
\hline $\mathrm{Cu}(\mathrm{mg})$ & 1.89 & 0.70 & 2.30 & 1.07 & 1.68 & 0.71 & 2.04 & 1.00 & 0.09 & $0.03^{*}$ \\
\hline $\mathrm{Fe}(\mathrm{mg})$ & $16 \cdot 50$ & 9.46 & 19.58 & 11.80 & $15 \cdot 16$ & $10 \cdot 43$ & 18.43 & $12 \cdot 76$ & $0 \cdot 16$ & $0.04^{*}$ \\
\hline $\mathrm{Mg}(\mathrm{mg})$ & 418.64 & $151 \cdot 28$ & 446.05 & $169 \cdot 21$ & $365 \cdot 74$ & 158.62 & 392.45 & $175 \cdot 78$ & $0.01^{*}$ & $<0.01^{*}$ \\
\hline$P(\mathrm{mg})$ & 1104.84 & 471.78 & $1119 \cdot 34$ & 473.12 & $1073 \cdot 16$ & $517 \cdot 27$ & $1088 \cdot 34$ & $518 \cdot 24$ & 0.42 & 0.43 \\
\hline $\mathrm{K}(\mathrm{mg})$ & $3416 \cdot 81$ & $1203 \cdot 94$ & $3428 \cdot 24$ & $1213 \cdot 70$ & $2824 \cdot 85$ & 1233.63 & $2850 \cdot 10$ & 1238.79 & $<0.01^{*}$ & $<0.01^{*}$ \\
\hline Se $(\mu \mathrm{g})$ & 88.49 & $44 \cdot 81$ & 95.43 & $50 \cdot 13$ & 98.88 & 61.99 & $107 \cdot 72$ & $65 \cdot 87$ & 0.34 & 0.43 \\
\hline $\mathrm{Na}(\mathrm{mg})$ & $2285 \cdot 20$ & 1081.57 & 2292.08 & 1086.66 & 2307.03 & $1041 \cdot 19$ & 2306.85 & 1045.95 & 1.00 & 0.92 \\
\hline $\mathrm{Zn}(\mathrm{mg})$ & 9.06 & 4.54 & $14 \cdot 10$ & 10.00 & 8.78 & 5.12 & 14.43 & 11.66 & 0.71 & 0.27 \\
\hline
\end{tabular}

${ }^{\star} P<0.05$ indicates statistical significance.

†Total includes dietary and supplements.

Table 4 Blood concentrations of selected minerals, total phenols (FC) and ferric-reducing antioxidant capacity (FRAP) at the end of the usual diet and the added-figs diet phases among American males and females ( $n$ 88), September-December 2008

\begin{tabular}{|c|c|c|c|c|c|}
\hline & \multicolumn{2}{|c|}{ Usual diet† } & \multicolumn{2}{|c|}{ Added-figs diet $†$} & \multirow[b]{2}{*}{$P$ value $\neq$} \\
\hline & Mean & SD & Mean & SD & \\
\hline $\mathrm{Fe}(\mu \mathrm{mol} / \mathrm{l})$ & $26 \cdot 6$ & 13.0 & $29 \cdot 4$ & $17 \cdot 4$ & 0.362 \\
\hline $\mathrm{Mg}(\mathrm{mmol} / \mathrm{l})$ & 0.75 & 0.41 & 0.77 & 0.44 & 0.657 \\
\hline $\mathrm{K}(\mathrm{mmol} / \mathrm{l})$ & 4.33 & $1 \cdot 10$ & 4.28 & 0.97 & 0.094 \\
\hline $\mathrm{Zn}(\mu \mathrm{mol} / \mathrm{l})$ & $16 \cdot 38$ & $4 \cdot 27$ & 15.97 & 4.27 & $0 \cdot 170$ \\
\hline $\mathrm{FC}(\mathrm{GAE} \S \mathrm{mmol} / \mathrm{l})$ & 1.36 & 0.33 & 1.34 & 0.31 & 0.040 \\
\hline FRAP $(\mathrm{mmol} / \mathrm{l})$ & 0.14 & 0.09 & 0.14 & 0.12 & 0.396 \\
\hline
\end{tabular}

†Values represent mean and standard deviation of two blood draws separated by 1 week.

$\ddagger P$ value for repeated-measure ANOVA adjusted for BMI.

$\S$ Gallic acid equivalents.

measurements were included $(P=0 \cdot 04)$. FC was marginally significant when the median of the figs-added phase was compared with that of the usual diet phase (Table 4).

\section{Food displacement}

Estimates of the percentage of food displacement after a 5-week supplementation with figs are shown in Table 5. The total fig intake during the added-figs diet phase is presented in the fourth column of Table 5, which reflects the mean values of the actual amount of figs consumed by the participants.

On average, the fig supplement consumed by study participants was $128 \mathrm{~g}$. We followed the percentage food displacement calculation method as explained elsewhere ${ }^{(10)}$. For example, $0 \%$ displacement means that the amount of food $i$ present in the added-figs diet phase is totally added to the supplemented diet. An estimate of $100 \%$ displacement means that food $i$ from figs replaced an equal amount of that food in the supplemented diet by reducing the intake of food $i$ from foods other than figs. A value between 0 and $100 \%$, therefore, indicates partial displacement and that a person was eating more of that food. A value of more than $100 \%$ means that food $i$ in the added-figs phase more than fully displaced that food, and the overall supplemented diet now contains less of this food due to eating figs. A negative percentage indicates that not only was there no displacement but that non-fig foods in the supplemented diet contained more of food $i$ than in the usual diet period ${ }^{(10)}$.

\section{Discussion}

Our present results indicate that simply prescribing a daily supplement of figs $(128 \mathrm{~g})$ can induce food modifications to most individuals' usual diet. The nutrient and mineral profile of the fig-supplemented diet produced an overall change in the habitual diet.

The current study confirmed these results and reported higher $\mathrm{Ca}, \mathrm{K}, \mathrm{Fe}$ and $\mathrm{Cu}$ intakes during the figsupplemented phase.

However, blood samples did not show any superiority of the fig-supplemented phase in any mineral. A number of explanations for these results may be relevant. First, it is possible that the 5-week trial period was not sufficient to see any changes in blood. Second, the high fibre content of figs could be a factor and the serving size may need to be increased to see an effect. Lastly, we may need to use different blood biomarkers to detect changes in blood.

The only significant variable in blood samples was FC, which is the biochemical test for 'total phenols' $(P=0.04)$. 
Table 5 Displacement of selected foods after following a 5-week supplementation with figs (mean values for three $24 \mathrm{~h}$ recalls for each food period) among American males and females ( $n$ 88), September-December 2008

\begin{tabular}{|c|c|c|c|c|c|c|}
\hline \multirow[b]{3}{*}{ Variable } & \multicolumn{3}{|c|}{ Diet } & \multicolumn{3}{|c|}{ Food displacement } \\
\hline & \multirow{2}{*}{$\frac{\text { Usual diet }(\mathrm{g})}{(H)}$} & \multirow{2}{*}{$\frac{\text { Added-figs diet }(\mathrm{g})}{(A)}$} & \multirow{2}{*}{$\frac{\text { Fig }(\mathrm{g})}{(S)}$} & \multirow{2}{*}{$\frac{\text { Absolute }(D)}{S+H-A}$} & \multicolumn{2}{|c|}{$\% \dagger$} \\
\hline & & & & & $D / S \times 100$ & SE \\
\hline Meat, fish and poultry & 150 & 286 & 128 & -9 & -7 & 112 \\
\hline Milk, cream, cheese and related products & 149 & 136 & 128 & 141 & 110 & 13 \\
\hline Fruits and fruit products & 292 & 300 & 128 & 120 & 94 & 21 \\
\hline Dried fruit & 10 & 48 & 128 & 91 & 71 & 2 \\
\hline Vegetables and vegetable products & 305 & 299 & 128 & 134 & 105 & 15 \\
\hline Grain products & 355 & 325 & 128 & 157 & 123 & 19 \\
\hline Soups, gravy and sauces & 154 & 159 & 128 & 123 & 96 & 20 \\
\hline Desserts & 36 & 30 & 128 & 133 & 104 & 7 \\
\hline Beverages & 1621 & 1406 & 128 & 343 & 268 & 72 \\
\hline Supplements and drugs & 0 & 0 & 128 & 128 & 100 & 0 \\
\hline
\end{tabular}

$H$, the intake of a food during the usual diet; $A$, the intake of that food during the added-figs diet period; $S$, the amount of fig intake in the fig phase; $D$, displacement of that food.

†Mean of percentage differences.

This result is similar to Vinson et al. ${ }^{(8)}$. These authors reported that dried fruits such as dried figs and plums have higher-quality antioxidants. They considered figs as in vivo antioxidants in man. However, we did not observe Vinson et al.'s study pattern with FRAP, which measures the antioxidant capacity of plasma ${ }^{(8)}$. Those researchers found that eating figs produces a significant increase in antioxidant capacity that lasts for $4 \mathrm{~h}$ after consumption. The reason for this difference could due to the different method they used, which is based on $\mathrm{IC}_{50}$ (the concentration to inhibit the oxidation by $50 \%$ ). The same result was produced in the study of Solomon et al. ${ }^{(15)}$, who used the Trolox equivalent antioxidant capacity (TEAC) test to measure total antioxidant capacity rather than FRAP. That study showed that figs had the highest levels of polyphenols and antioxidant capacity.

Our calculations of displacement estimates show that figs displaced foods in the following order (from smallest to greatest percentage displacement): soup/gravy/sauce, fruits and dried fruits. However, it is difficult to compare these results with other studies because to our knowledge the present study is the first one to measure food displacement patterns with figs. By focusing on fig consumption, it is perhaps not surprising that most other food groups could be displaced. The estimated displacement suggests that an additional $4 \%$ of desserts, $5 \%$ of vegetables, $10 \%$ of dairy products, $23 \%$ of grain products and $168 \%$ of beverages from other sources were eliminated. Given that the intakes of fibre and carbohydrate were greater in the fig-supplemented diet period, it is possible that figs induced a specific displacement pattern that reduced the intake of most food groups, or increased the intake of complex carbohydrates such as fruit products and dried fruits in the supplemented diet. Our results also indicated that participants started to eat more in the fig phase. However, we could not explain this result. In addition, there is no study investigating the effect of figs on food displacement with which to compare our results.
The present study has several strengths, such as the randomized controlled design and adequate power. We used repeated $24 \mathrm{~h}$ recalls, which are increasingly recommended to avoid the limitations of other methods that require more effort on the part of the participant ${ }^{(4,5)}$. However, a potential limitation is the inability to obtain adequate blood samples from all participants who completed the study. To avoid seasonal changes, the study was conducted within a short time period. Furthermore, the participants were free living, which can potentially cause threats to validity when assessing dietary intake, leading to under-reporting and biased reporting of dietary intake ${ }^{(16)}$. In addition there was no washout period; however, due to the short half-life of figs and study duration, it would be difficult to notice a major effect when figs are added to the diet. The study will help future studies in establishing a baseline for the effects of figs on diet. Lastly, it may be difficult to generalize these results to other populations, as this population had a high fibre intake at baseline and was health conscious and physically active.

\section{Conclusion}

Dried figs may have the potential to affect the levels of $\mathrm{Ca}, \mathrm{Mg}$ and $\mathrm{K}$. These fruits are also available during the year at any time and are a good source of fibre and several minerals. However, further studies are needed to understand the long-term effect of fig intake.

\section{Acknowledgements}

Financial support: The study was funded in its entirety by the California Fig Advisory Board. The California Fig Advisory Board had no role in the design, analysis or writing of this article. Conflict of interest: None. Authorship: H.K.A., S.T. and E.H. were responsible for the study design 
and data collection. Z.S.N. was responsible for the statistical analyses. H.K.A., E.H. and K.J.-S. contributed to the interpretation of the results. H.K.A. and E.H drafted the manuscript. Ethics of human subject participation: The study was conducted according to the guidelines laid down in the Declaration of Helsinki. The research protocol was approved by the Institutional Review Board of Loma Linda University.

\section{References}

1. World Health Organization (2003) Diet, Nutrition and the Prevention of Chronic Diseases. Report of a Joint WHO/ FAO Expert Consultation. WHO Technical Report Series no. 916. ftp://ftp.fao.org/docrep/fao/005/ac911e/ac911e00.pdf (accessed December 2013).

2. Fung TT, Rimm EB, Spiegelman D et al. (2001) Association between dietary patterns and plasma biomarkers of obesity and cardiovascular disease risk. Am J Clin Nutr 73, 61-67.

3. Lauber RP \& Sheard NF (2001) The American Heart Association Dietary Guidelines for 2000: a summary report. Nutr Rev 59, 298-306.

4. Institute of Medicine, Food and Nutrition Board (2010) Dietary Reference Intakes for Vitamin C, Vitamin E, Selenium, and Carotenoids. A Report of the Panel on Dietary Antioxidants and Related Compounds. Washington, DC: National Academy Press; available at http://fnic.nal.usda. gov/dietary-guidance/dietary-reference-intakes/dri-tables

5. Institute of Medicine, Food and Nutrition Board (2005) Dietary Reference Intakes for Energy, Carbohydrate, Fiber, Fat, Fatty Acids, Cholesterol, Protein, and Amino Acids (Macronutrients). Washington, DC: National Academy Press.

6. European Food Safety Authority, Scientific Committee on Food, Scientific Panel on Dietetic Products, Nutrition and
Allergies (2006) Tolerable Upper Intake Levels for Vitamins and Minerals. http://www.efsa.europa.eu/en/ndatopics/ docs/ndatolerableuil.pdf (accessed December 2013).

7. Sun-Maid Growers of California (2010) The Facts on Raisins \& Dried Fruits. http://www.sunmaid.com/book/US_Edition_ Ch5_bookmarks.pdf. (accessed December 2013).

8. Vinson J, Zubik L, Bose P et al. (2005) Dried fruits: excellent in vitro and in vivo antioxidants. J Am Coll Nutr 24, 44-50.

9. Peterson JM, Montgomery S, Haddad E et al. (2011) Effect of consumption of dried California Mission figs on lipid concentrations. Ann Nutr Metab 58, 232-238.

10. Jaceldo-Siegl K, Sabaté J, Rajaram S et al. (2004) Long-term almond supplementation without advice on food replacement induces favourable nutrient modifications to the habitual diets of free-living individuals. Br J Nutr 92, 533-540.

11. Marlett JA \& Cheung TF (1997) Database and quick methods of assessing typical dietary fiber intakes using data for 228 commonly consumed foods. J Am Diet Assoc 97, 1139-1151.

12. Vinson JA (1999) The functional food properties of figs. Cereal Food World 44, 82-87.

13. Serafini M, Maiani G \& Ferro-Luzzi A (1998) Alcohol-free red wine enhances plasma antioxidant capacity in humans. $J$ Nutr 128, 1003-1007.

14. Benzie IFF \& Strain JJ (1996) The ferric reducing ability of plasma (FRAP) as a measure of 'antioxidant power', the FRAP assay. Anal Biochem 239, 70-76.

15. Solomon A, Golubowicz S, Yablowicz Z et al. (2006) Antioxidant activities and anthocyanin content of fresh fruits of common fig (Ficus carica L.). J Agric Food Chem 54, $7717-7723$.

16. Miller T, Abdel-Maksoud MF, Crane LA et al. (2008) Effects of social approval bias on self-reported fruit and vegetable consumption: a randomized controlled trial. Nutr J 7, 18.

17. US Department of Agriculture, Nutrient Data Laboratory. (2011) USDA Nutrient Database for Standard Reference. http://ndb.nal.usda.gov/ (accessed July 2013). 